\title{
Práticas e comportamentos de liderança na gestão dos recursos humanos escolares
}

\author{
Andreia Rubina da Conceição Costa a \\ António V. Bento ${ }^{a}$
}

\section{Resumo}

Num mundo globalizado e complexo em que o capital humano assume centralidade em temáticas associadas à liderança das organizações escolares e consequente Gestão de Recursos Humanos, urge perceber que perceções têm os liderados, pessoal docente e não docente, acerca das práticas e comportamentos da liderança do Diretor escolar. Esta pesquisa de natureza mista, privilegiou como estratégia metodológica o estudo de caso, incidindo sobre uma Escola Básica dos $2^{\circ}$ e $3^{\circ}$ Ciclos da Região Autónoma da Madeira. Foi administrado, ao pessoal docente e não docente da escola, o questionário LPI - Observer (Leadership Practice Inventory) de Kouzes e Posner. A análise de conteúdo recaiu sobre o Projecto Educativo de Escola e o Plano Anual de Escola. Concluíu-se que, na opinião dos inquiridos, as práticas de liderança que deverão ser privilegiadas por um líder eficaz são "Permitir que os outros ajam" e "Encorajar a vontade".

Palavras-chave: Organizações escolares. Gestão de recursos humanos. Liderança. Práticas de liderança.

\section{Introdução}

A atualidade, global e complexa, caracterizada pelo paradigma científicotecnológico, tem provocado, nos vários domínios da vivência humana, alterações profundas e constantes. Também as organizações, e em particular as escolares, deparam-se com mudanças que, na maior parte das vezes, são impulsionadas por fatores externos a estas. Parafraseando Guerra (2000, p. 54), a escola tem "de estar de sobreaviso relativamente aos novos contextos sociais e às novas exigências da sociedade", pois, é do conhecimento geral que, cada vez mais,

\footnotetext{
a Universidade da Madeira - UMa. Funchal, Portugal.
} 
são exigidos às escolas elevados padrões de excelência e qualidade que se deverão traduzir no sucesso educativo dos seus alunos.

Nesta senda de pensamento, Chiavenato (1993) refere que é importante para qualquer organização analisar a sua eficiência e eficácia, e que estas relacionam-se, naturalmente, com os seus Recursos Humanos. É evidente que qualquer organização tem de se focalizar, primordialmente, no seu capital humano, pois é nas pessoas que reside o conhecimento e a criatividade capazes de as adaptar às constantes mudanças. Desta forma, os líderes/gestores de Recursos Humanos têm sido desafiados a repensar o papel dos seus Recursos Humanos, dando mais valor ao ser humano em todas as suas dimensões.

Nas organizações escolares, este aspecto também não deverá ser descurado pelo que os gestores de Recursos Humanos escolares, nomeadamente, os Presidentes dos Conselhos Executivos, deverão dar a devida atenção à forma como é gerido e, fundamentalmente, liderado o Pessoal Docente e Não Docente. Mesmo Costa (2003) refere que as escolas excelentes são aquelas em que os líderes são pessoas que se destacam. A liderança assume assim um papel relevante em todo o tipo de organizações, nomeadamente as escolares, pois, segundo Motta (1999, p. 221), "liderar significa descobrir o poder que existe nas pessoas, torná-las capazes de criatividade, auto-realização e visualização de um futuro melhor para si próprias e para a organização em que trabalham”.

Desta forma, impõe-se, no contexto das organizações educativas, analisar a influência das práticas e comportamentos da liderança, especialmente direcionadas para a vertente da gestão dos seus Recursos Humanos. O presente trabalho de investigação, de natureza mista, privilegiando-se o estudo de caso, foi realizado no ano letivo de 2010-2011 numa escola pública da Região Autónoma da Madeira (Portugal); fizemos a análise de conteúdo pormenorizada dos Projeto Educativo de escola (PEE) e do Plano Anual de Escola (PAE) e administrámos o Inventário das Práticas de Liderança (LPI) de Kouzes e Posner (2003a) ao pessoal docente e não docente da escola. Tivemos como objetivo fundamental analisar as perspetivas dos liderados no que concerne à sua perceção das práticas e comportamentos da liderança. Também nos propusemos a averiguar que práticas e comportamentos de liderança deverão ser privilegiados num líder eficaz segundo a perspetiva destes dois grupos.

No que concerne à sua estrutura, este trabalho de investigação é constituído por cinco partes. A primeira parte reporta-se a esta introdução seguida do enquadramento teórico, em que abordamos teoricamente a Gestão de Recursos 
Humanos e a Liderança. Seguidamente refere-se à metodologia utilizada, nomeadamente, o contexto do estudo de caso, os instrumentos de recolha de dados e os procedimentos adotados. Depois apresentamos e interpretamos os dados recolhidos e redigimos, por último, as conclusões.

\section{Gestão de recursos humanos e liderança}

Segundo Bilhim (2006, p. 29), a "gestão de recursos humanos diz respeito a todas as decisões e acções de gestão que afectam a relação entre as organizações e os seus empregados". Por conseguinte, envolve todas as atividades relacionadas com a "selecção, formação, desenvolvimento, recompensas e relações com os empregados" (BILHIM, 2006, p. 29). Na mesma senda de pensamento, Lopes e Barrosa (2008, p. 189) encaram a gestão de pessoas como a "forma como a organização gere, desenvolve o conhecimento e o potencial do seu pessoal, em termos individuais, em grupo e organizacionais e planeia estas atividades com vista a suportar as políticas, estratégias e o efectivo funcionamento dos seus processos".

Ao analisarmos algumas das definições do conceito Gestão de Recursos Humanos, podemos salientar o termo estratégia. Por conseguinte, para Silva (2000, p. 231), a estratégia é uma ferramenta com um grande potencial para as organizações para melhor gerir os condicionalismos próprios das permanentes mudanças. No entanto, nas escolas, assistimos a dificuldades na sua implementação que, de acordo com Silva (2000, p. 232), advêm destas não estarem moldadas pela/para a mudança. Segundo este autor, as suas caraterísticas organizacionais, nomeadamente, a estabilidade, a rigidez estrutural, a forte hierarquização, a reatividade, a valorização da experiência do passado, a minimização do risco, a preocupação em gerar consenso, são entraves a uma ação estratégica que "exige das organizações fluidez estrutural e funcional, enfrentamento de riscos, busca criativa de novas soluções, aceitação da mudança", entre outros (p. 232).

Bilhim (2006), Lopes e Barrosa (2008) e Camara, Guerra e Rodrigues (2010) referem que, na atualidade, foi posta de parte a ideia de considerar a gestão de recursos humanos como meramente administrativa ou tática para serem valorizados aspectos relacionados com o desenvolvimento das pessoas. As pessoas é que são capazes de aprender permanentemente e responder às exigências das constantes mudanças e não os aspectos técnicos (tecnologia) (Rodrigues, 2008, p. 23). O importante a reter a nível organizacional é que não se deve centrar somente nos aspectos técnicos, pois, ao o fazerem, estarão a lhes escapar o fundamental: "o primado humano, o único capaz de fazer a diferença em contextos onde o acesso e o domínio da tecnologia são apenas condições de partida, e não de chegada, para uma efectiva eficácia empresarial" (Rodrigues, 2008, p. 23). 
No contexto escolar da Região Autónoma da Madeira (RAM), de acordo com o diploma de autonomia e gestão das escolas, fazem parte das competências do Conselho Executivo, no que concerne à gestão dos recursos humanos, de acordo com a alínea f do ponto 2 do artigo 15, a distribuição de serviço do pessoal docente e não docente, e na alínea 1 , proceder à seleção e recrutamento de pessoal docente e não docente, salvaguardado o regime legal dos concursos. Dentro da sua autonomia administrativa, de acordo com os artigos n 14 e n 19 do Decreto-Lei $n^{\circ} 43 / 1989$, de 3 de Fevereiro, compete à escola, entre outros, participar na formação e atualização dos docentes, participar, gradual e crescentemente, na seleção e recrutamento do pessoal docente, de acordo com regulamentação a definir, atribuir o serviço docente, dar parecer sobre pedidos de colocação de pessoal docente em regime especial, inventariar as suas necessidades quanto ao número e qualificação do pessoal técnico, técnico-profissional, administrativo, operário e auxiliar, definir critérios de distribuição de serviço ao pessoal não docente e estabelecer critérios para a selecção de pessoal a contratar a prazo, incluindo casos de substituição temporária, e proceder à sua contratação.

Na RAM, o órgão hierarquicamente superior às escolas que tutela a matéria de gestão dos Recursos Humanos é a Direção Regional de Administração Educativa (DRAE), dependência da Secretaria Regional de Educação e Cultura (SREC). Na RAM, e na mesma linha de pensamento de Lima (2007), as escolas estão dependentes das orientações emanadas por uma instância externa e superior, a DRAE, no respeitante aos aspetos mais relevantes da gestão dos seus recursos humanos, como por exemplo, ao seu recrutamento e seleção, à remuneração e avaliação do desempenho. A DRAE funciona como uma organização reguladora da aplicação das políticas emanadas pela SREC e às escolas compete colocá-las em prática, dentro do seu restrito campo de autonomia.

Segundo Bento (2008, p. 1), dentro da mesma linha de pensamento de Fullan (2000),

o líder, em geral, tem sido visto como alguém que possui determinadas características inatas ou adquiridas, alguém que se adapta às circunstâncias e ao contexto em que a organização se insere e alguém que gere conflitos e exerce influência em ambientes ambíguos, complexos e incertos.

Muitas são as definições de liderança que poderemos encontrar na diversa bibliografia existente. Por exemplo, Hooper e Potter (2010, p. 62) mencionam que "a liderança já não é comando, controlo e forçar as pessoas a conformarem-se", a liderança é "conquistar corações e mentes através de uma eficaz liderança 
persuasiva, utilizando as relações e as capacidades de comunicação, e é também analisar as situações do ponto de vista das outras pessoas".

É de realçar que existe muita controvérsia entre os conceitos liderança e gestão ou chefia. Para Afonso (2009) e Lopes e Barrosa (2008), existem mesmo diferenças entre a figura do líder e a do gestor. Nos processos de liderança, o líder tem capacidade em controlar, de forma interna e externa, as pessoas, nomeadamente, as suas perceções, motivações e valores enquanto que, nos processos de gestão ou chefia existe um controle externo sobre as pessoas, sobre os resultados ou ações, não existindo perceção, por parte do administrador, sobre as suas motivações e valores. Afonso (2009), Hooper e Potter (2010) e Krause (1999) são de opinião que a existência destes dois processos depende da situação em que o líder e os liderados estão inseridos, e que nas organizações bem-sucedidas é necessário ter umas pessoas boas na gestão e outras na liderança.

Também no contexto escolar, na atualidade, é atribuída redobrada importância à gestão e administração das instituições escolares, em particular, às suas lideranças. É, por conseguinte, reconhecido que as práticas de liderança influenciam a qualidade e eficácia das organizações escolares. Contudo, as escolas têm características e contextos muito específicos que tornam a sua liderança em algo muito singular.

As escolas têm um papel muito importante na sociedade, pois, para todos, estas têm o dever de construir cidadãos melhores com o intuito de se traduzir, consequentemente, numa sociedade melhor (GUERRA, 2002, p. 10). Torres e Palhares (2009) referem que, à semelhança dos restantes países, também no contexto português, os gestores e líderes escolares encontram-se submetidos a grandes pressões políticas, mecanismos de controle, de inspeção e de avaliação. Por outro lado, o Presidente do Conselho Executivo tem o compromisso de cuidar das necessidades da escola como uma instituição, servindo os seus propósitos e aqueles que lutam para os atingir, como também, proteger a sua integridade institucional. Desta forma, os líderes escolares são educadores e baseiam o seu trabalho na aprendizagem, no ensino e na melhoria da escola sendo, assim, sendo considerados agentes morais e defensores sociais das crianças e das restantes pessoas da comunidade educativa (FULLAN, 2000; GREENFIELD, 1999; SERGIOVANNI, 2004). Esta voz moral faz toda a diferença na liderança das organizações escolares, pois permite considerar a liderança como o desenvolvimento de um grupo de pessoas que têm objetivos comuns em detrimento da gestão burocrática (SERGIOVANNI, 2004). Outro aspecto a salientar é o fato de a liderança escolar ser dispersa, pois percorre os diversos setores da escola, sendo assumida por vários elementos da escola de uma forma partilhada (COSTA, 2000; FORMOSINHO; MACHADO, 2000), destacando-se, desta forma, princípios fundamentalmente democráticos. 
No sentido de encontrar um modelo de práticas de uma liderança exemplar, Kouzes e Posner (2009) enunciaram, no seu entender, cinco práticas para uma liderança exemplar relacionadas com os comportamentos do líder e não com a sua personalidade. Estas práticas servem de modelo de orientação para qualquer líder que queira conseguir feitos extraordinários dentro da sua organização (Quadro 1).

\section{Aspectos metodológicos}

Na presente investigação, foi utilizado, como estratégia de pesquisa, o estudo de caso pelo que a mesma se enquadra no paradigma dos estudos qualitativos. Segundo Yin (2001, p. 32), "um estudo de caso é uma investigação empírica que: investiga um fenômeno contemporâneo dentro do seu contexto da vida real, especialmente quando os limites entre o fenômeno e o contexto não estão claramente definidos".

Por outro lado, a natureza do nosso estudo tem também caraterísticas do paradigma dos estudos quantitativos, pois utilizou, como um dos instrumentos de recolha de dados, o inquérito por questionário que posteriormente foi tratado através da análise estatística. Para Yin (1993), o estudo de caso não implica nenhuma forma específica de recolha de dados, os quais podem ser quantitativos e qualitativos. Tanto Bell (2008) como Sousa (2005) apontam para esta possibilidade dos investigadores utilizarem técnicas qualitativas e quantitativas sendo que, este último investigador, refere que mesmo nas investigações qualitativas mais radicais:

têm vindo a usar cada vez com maior frequência o tratamento estatístico nas suas investigações de tal modo que nos dias de hoje já quase nem se faz distinção entre perspectivas qualitativas e quantitativas. É a investigação que requer esta ou aquela metodologia, independentemente das posições teóricas do investigador (SOUSA, 2005, p. 291).

\subsection{Contextualização do estudo de caso}

Para a realização da presente investigação, foi escolhido o caso de uma escola pública urbana do ensino básico do $2^{\circ}$ e $3^{\circ}$ Ciclos com 14 anos de funcionamento. A escola é um edifício constituído por seis pisos com 27 salas de aula e seis laboratórios, dois parques de estacionamento, dois polidesportivos e um ginásio (PEE, p. 14). No ano letivo em que decorreu a presente investigação (2010/2011), a escola iniciou o ano com 106 docentes ao serviço. O Conselho Executivo é composto por três docentes do quadro da escola que estão nestas funções desde a sua abertura. Em relação ao Pessoal Não Docente, a escola teve ao seu dispor 51 elementos. O número de alunos, no início do ano letivo 2010/2011, era de 688 alunos distribuídos por 33 turmas do $5^{\circ}$ ano ao $9^{\circ}$ ano de escolaridade. 
Quadro 1. As cinco práticas de liderança exemplar.

\begin{tabular}{|c|c|}
\hline Prática & Análise \\
\hline Mostrar o caminho & $\begin{array}{l}\text { É liderar a partir daquilo que acredita, partindo da } \\
\text { clarificação dos seus valores pessoais. Significa que o líder } \\
\text { terá de dar o exemplo e ser o modelo de comportamento } \\
\text { que espera dos constituintes. Em suma, consiste em alcançar } \\
\text { o direito e o respeito para liderar os seus constituintes } \\
\text { através do envolvimento e ação direta sobre estes. }\end{array}$ \\
\hline ur uma visão conjunta & $\begin{array}{l}\text { Refere-se ao líder ter uma visão atrativa para o futuro } \\
\text { da organização envolvendo os seus constituintes na } \\
\text { mesma. Para ter o envolvimento dos outros o líder terá } \\
\text { de os conhecer, nomeadamente, os seus sonhos, as suas } \\
\text { esperanças, aspirações e valores. }\end{array}$ \\
\hline processo & $\begin{array}{l}\text { É procurar novas ideias e reconhecer as que são boas, é } \\
\text { desafiar o sistema organizacional para mudar. Comporta } \\
\text { experimentar, correr riscos e errar. Os erros deverão ser } \\
\text { encarados como momentos de aprendizagem, por seu } \\
\text { turno, os pequenos sucessos devem ser considerados } \\
\text { vitórias com o intuito de incentivar a que os constituintes } \\
\text { voltem a experimentar. }\end{array}$ \\
\hline os outros ajam & $\begin{array}{l}\text { Implica a promoção da colaboração e da confiança mútua. } \\
\text { Esta prática aponta, por conseguinte, para a valorização } \\
\text { dos outros, através da distribuição do poder, aumentando, } \\
\text { consequentemente, a sua autoconfiança. Para haver uma } \\
\text { responsável distribuição do poder é necessário aumentar } \\
\text { a competência dos constituintes através, por exemplo, de } \\
\text { formação. }\end{array}$ \\
\hline Encorajar a vontade & $\begin{array}{l}\text { Reporta-se a reconhecer as contribuições de todos } \\
\text { através de celebrações das vitórias e dos valores, criando, } \\
\text { consequentemente, um espírito de comunidade. }\end{array}$ \\
\hline
\end{tabular}

Fonte: Kouzes e Posner (2009, p. 48).

\subsection{Instrumentos de recolha de dados}

Com a investigação documental efetuada, construímos um referencial teórico com o que já existe, utilizando fundamentalmente as contribuições de vários autores e os estudos já desenvolvidos na área.

Seguidamente, efetuamos a análise de conteúdo do Projeto Educativo de Escola (PEE) e do Plano Anual de Escola (PAE) tendo em conta os procedimentos que 
são enunciados por Sousa (2005). No intuito de registar o mais importante e encontrar as ideias principais, foi dada uma leitura cuidada a estes documentos tentando sempre relacionar a informação retida com as ideias desenvolvidas por Kouzes e Posner (2009) no modelo das "5 Práticas de Liderança Exemplar".

Para a elaboração da análise de conteúdo, consideramos cada uma das práticas de liderança eficaz, enunciadas por Kouzes e Posner (2009), como uma categoria de análise. A cada prática de liderança foram associadas unidades de análise, conforme se espelha no Quadro 2.

A análise de conteúdo efetuada teve o papel de melhor corroborar evidências que, posteriormente, foram retiradas pela análise dos dados do questionário e/ou acrescentar mais algumas informações pertinentes para o estudo de caso.

Embora tivéssemos iniciado a construção de um questionário, quando estávamos a efetuar as pesquisas para a realização da revisão da literatura, decidimos utilizar um questionário que se encontra validado internacionalmente, o Inventário das Práticas de Liderança - LPI (Leadership Practice Inventory), desenvolvido por Kouzes e Posner (2003a). Este questionário foi utilizado em alguns trabalhos de investigação, nomeadamente, Ribeiro e Bento (2009; 2010) e Sandbakken (2004), entre outros, e, constatando que se adequavam ao estudo que estávamos a realizar, decidimos utilizá-lo, pela sua reconhecida qualidade.

No início do questionário, optamos por colocar várias informações acerca do objetivo do estudo e indicações de como proceder para a seleção das respostas. Seguidamente segue-se uma seção com questões destinadas à caracterização dos inquiridos, correspondendo à Parte 1 do questionário. A segunda parte do questionário é constituída pelas questões do LPI (KOUZES; POSNER, 2003a). Cada afirmação tem uma pontuação de cinco pontos numa escala distribuída da seguinte forma: 1 - "Nunca", 2 - "Ocasionalmente", 3 - "Algumas vezes", 4 - "Muitas vezes" e 5 - "Frequentemente".

Este questionário é composto por 30 questões que avaliam as práticas de liderança, agrupando-as nos cinco grandes domínios ou práticas de liderança. No Quadro 3, podemos verificar a que domínio é que pertence cada afirmação do LPI.

Tendo em conta as nossas questões de investigação, optamos por fazer uma adaptação ao questionário, nomeadamente, o acréscimo de mais uma coluna, de forma a podermos recolher, num mesmo momento, também as opiniões dos inquiridos quanto às práticas de liderança que deverão ser observadas num líder eficaz. 
Quadro 2. Categorias e unidades de análise.

\begin{tabular}{|l|c|}
\hline Categorias & Unidades de análise \\
\hline Mostrar o caminho & Clarificação dos valores comuns \\
\cline { 2 - 2 } & Dar o exemplo \\
\hline Inspirar uma visão conjunta & Visão atrativa do futuro \\
\cline { 2 - 2 } & Atrair os outros numa visão comum \\
\hline Desafiar o processo & Procurar oportunidades \\
\hline \multirow{2}{*}{ Permitir que os outros ajam } & Experimentar e correr riscos \\
\cline { 2 - 2 } & Fomentar a colaboração \\
\hline Encorajar a vontade & Dar força aos outros \\
\cline { 2 - 2 } & Reconhecer contributos \\
\cline { 2 - 2 } & Celebrar valores e vitórias \\
\hline
\end{tabular}

Fonte: Adaptado de Kouzes e Posner (2009).

O questionário foi aplicado a todo o Pessoal Docente (PD) e Pessoal Não Docente (PND) da escola. A percentagem de questionários devolvidos foi superior no grupo do PND, tendo sido de 70,6\%, enquanto no grupo do PD foi de 49,1\%. Independentemente da função, verifica-se que $56,1 \%$ da população em estudo responderam ao questionário, o que corresponde a uma amostra que representa mais de metade da população. Embora mais de metade da população tenha respondido ao questionário, não podemos afirmar que seja representativa ou significativa da população. O grupo do PND é representativo da população, ou seja, os resultados obtidos para este grupo podem ser conclusivos para todos os Não Docentes da escola. No caso do PD, já não se pode generalizar as conclusões para todos os Docentes, pelo que, os resultados obtidos só são conclusivos para os 52 elementos que entregaram o questionário.

\section{As práticas e comportamentos identificados}

\subsection{Análise de conteúdo do Projeto Educativo de Escola (PEE) e do Plano Anual de Escola (PAE)}

As práticas de liderança exemplar que se encontram mais frequentemente espelhadas no PEE são "Permitir que os outros ajam", com uma percentagem total de $48,8 \%$. Esta percentagem está distribuída pelas suas unidades de análise da seguinte forma: 36,6\% para "Fomentar a colaboração" e 12,2\% para "Dar força 
aos outros". Podemos, então, concluir que no PEE estão privilegiados aspectos relacionados com a colaboração e a confiança. A vertente mais enfatizada desta prática de liderança, neste documento, "Fomentar a colaboração", segundo Kouzes e Posner (2009), está relacionada com o incentivar o estabelecimento de relações humanas saudáveis entre todos os constituintes, tendo como consequência, o reforço da confiança mútua e da colaboração. A análise de conteúdo do PAE veio corroborar algumas das conclusões retiradas da análise de conteúdo do PEE visto que, tal como no PEE, a prática "Permitir que os outros ajam" é a que possui maior registo de ocorrências $(46,6 \%)$.

\subsection{O questionário}

Quanto à caracterização dos inquiridos, constatamos que do total dos 88 inquiridos, 52 pertencem à categoria do $\mathrm{PD}$, correspondendo a uma percentagem de $59,1 \%$, e 36 pertencem ao PND, com uma percentagem de $40,9 \%$. Quanto ao gênero, $83 \%$ do total dos inquiridos são do sexo feminino e $17 \%$ masculino. A idade mínima dos inquiridos é de 29 anos enquanto a máxima é de 62 anos. $\mathrm{Na}$ análise por função, a idade mínima do grupo dos Docentes é de 29 anos e a máxima de 59 anos, sendo a sua idade média de 42 anos. No grupo do PND, a idade mínima é de 30 anos e a máxima de 62 anos, verificando-se uma idade média de aproximadamente 48 anos.

Quanto ao tempo de serviço, o tempo de serviço mínimo é de um ano e o máximo de 36 anos. Segundo a função, no grupo do PD também se verificam estes tempos mínimos e máximos, tendo-se registado um tempo de serviço médio de 17 anos. No grupo do PND, o tempo de serviço mínimo é de 4 anos e o máximo é igual ao dos docentes (36 anos). Neste grupo, a idade média de tempo de serviço é de, aproximadamente, 48 anos. Relativamente ao tempo de serviço na escola, existe um mínimo de um ano e um máximo de 17 anos para

Quadro 3. Agregação das questões de acordo com o domínio de liderança.

\begin{tabular}{|l|c|}
\hline Prática de Liderança & Afirmação do LPI \\
\hline Mostrar o caminho & $1,6,11,16,21$ e 26 \\
\hline Inspirar uma visão conjunta & $2,7,12,17,22$ e 27 \\
\hline Desafiar o processo & $3,8,13,18,23$ e 28 \\
\hline Permitir que os outros ajam & $4,9,14,19,24$ e 29 \\
\hline Encorajar o coração & $5,10,15,20,25$ e 30 \\
\hline
\end{tabular}

Fonte: Adaptado de Kouzes e Posner (2003b, p. 20-21). 
o PD. No grupo do PND, existe um mínimo de cinco anos e um máximo de 14 anos, de exercício de funções nesta escola. O tempo de serviço na escola, no grupo dos Docentes é em média de oito anos, enquanto no grupo do PND é de 12 anos pelo que é na categoria do PND que existem profissionais com mais tempo de serviço na escola.

No que concerne às habilitações literárias, no grupo do $\mathrm{PD}$, surgem características diferentes comparativamente às do grupo do PND, que se podem justificar pelos próprios requisitos para exercer a profissão de docente. Desta forma, é natural que a grande maioria dos Docentes tenham a licenciatura enquanto no grupo do PND, as percentagens mais altas diluem-se pelos níveis de ensino mais baixos de ensino: $2^{\circ}$ Ciclo (33,3\%), $12^{\circ}$ ano $(22,2 \%)$ e $3^{\circ}$ Ciclo $(19,4 \%)$.

A segunda parte do questionário, constituída pelas questões do LPI (Kouzes \& Pousner), pretendeu aferir que comportamentos e/ou características são observadas pelos inquiridos no líder atual e as que consideram que um líder eficaz deverá privilegiar. É de salientar que, no presente estudo, os valores do Alpha de Cronbach ${ }^{1}$ e respetiva consistência interna para os domínios que avaliam as características presentes no líder atual e para os que avaliam as que devem estar presentes num líder eficaz variaram entre 0,856 e 0,910 (boa e muito boa).

A prática de liderança mais frequentemente percecionada pelos inquiridos no Presidente do Conselho Executivo é "Permitir que os outros ajam" que apresenta um valor médio de 23,31. Ou seja, segundo os inquiridos, o líder privilegia práticas relacionadas com o promover a colaboração de todos, fomentando os objetivos cooperativos e construindo confiança mútua; e a valorização dos outros através da partilha do poder e da formação. Constatamos que este resultado foi também obtido com a análise de conteúdo do PEE e do PAE, sendo que, no primeiro documento, registramos $48,78 \%$ de ocorrências desta prática e, no segundo, $46,66 \%$. Este resultado foi o encontrado também por Ribeiro e Bento (2009) e Sadbakken (2004) nas suas investigações.

Importa salientar que os aspectos relacionados com a prática "Permitir que os outros ajam" são valorizados por vários investigadores, nomeadamente, Bilhim (2006), Costa (2000), Fonseca (2000), Formosinho e Machado

O coeficiente alfa de Cronbach foi apresentado por Lee J. Cronbach, em 1951, como uma forma de estimar a confiabilidade de um questionário aplicado numa investigação. Ele mede a correlação entre respostas $n$ um questionário através da análise das respostas dadas pelos respondentes, apresentando uma correlação média entre as perguntas. $O$ coeficiente $\alpha$ é calculado a partir da variância dos itens individuais e da variância da soma dos itens de cada avaliador de todos os itens de um questionário que utilizem a mesma escala de medição (MARÔCO, 2007). 
(2000), Hooper e Potter (2010), Lopes e Barrosa (2008), Rodrigues (2008) e Sergiovanni (2004), e em situações de liderança.

Quanto às práticas de liderança exemplar que deverão ser privilegiadas por um líder eficaz, os dois grupos (PD e PND) divergem de opinião. Observamos que, para o PD, a prática a que atribuem maior importância é "Permitir que os outros ajam". Por seu turno, para o PND, a prática que um líder eficaz deverá privilegiar é "Encorajar a vontade". Por conseguinte, o PD privilegia num líder a valorização dos outros, através da distribuição do poder, aumentando, necessariamente, a sua autoconfiança. Para estes, o líder eficaz deverá promover a colaboração e a confiança mútua. Para o PND, é importante que o líder reconheça principalmente as contribuições de todos através de celebrações das vitórias e dos valores, criando, assim, um espírito de comunidade. É de salientar que uma vez que os valores médios obtidos pelo PD são significativamente superiores aos obtidos aos do PND, podemos afirmar que são os Docentes os que privilegiam mais as práticas de todos os cinco domínios da liderança para que um líder seja eficaz. Por outro lado, os dados fornecem evidência suficiente para afirmar que os inquiridos consideram que no líder atual, apesar de ter práticas e comportamentos de liderança eficaz, pois as médias em cada um dos domínios são altas, os mesmos são significativamente diferentes do que eles consideram ser importante observar numa liderança eficaz.

Relativamente à comparação das percepções do PD e do PND acerca das práticas da liderança do Presidente do Conselho Executivo, existem percepções significativamente diferentes entre o PD e o PND, pois os valores de prova são inferiores a 0,05 nos testes estatísticos $t$-Student ${ }^{2}$ e Mann-Whitney. ${ }^{3}$ Só não temos evidência suficiente para afirmar que a opinião do PD e do PND é significativamente diferente no domínio "Encorajar a vontade", pois o valor de prova encontrado foi 0,055 que é superior a 0,05 . Observamos que os valores médios mais altos registam-se no PD, existindo então evidência suficiente para afirmar que são os Docentes os que consideram que as práticas e comportamentos de uma boa liderança estão mais presentes no atual líder.

\footnotetext{
2 O teste $\mathbf{t}$ de Student ou somente teste $\mathrm{t}$ é um teste de hipótese que usa conceitos estatísticos para rejeitar ou não uma hipótese nula quando a estatística de teste $(t)$ segue uma distribuição $t$ de Student. Essa premissa é normalmente usada quando a estatística de teste, na verdade, segue uma distribuição normal, mas a variância da população $\sigma^{2}$ é desconhecida. Nesse caso, é usada a variância amostral $s^{2}$ e, com esse ajuste, a estatística de teste passa a seguir uma distribuição t de Student (MARÔCO, 2007).

3 Em estatística, o teste $U$ de Mann-Whitney (também chamado de Mann-Whitney-Wilcoxon, teste de Wilcoxon rank sum ou o teste de Wilcoxon-Mann-Whitney) é um teste não paramétrico aplicado para duas amostras independentes. É de fato a versão da rotina de teste não-paramétrico de $t$ de Student. Ele foi inicialmente proposto em 1945 por Frank Wilcoxon com os mesmos tamanhos de amostra e estendido para tamanhos de amostras arbitrárias e de outras maneiras por Henry B. Mann e DR Whitney em 1947 (MARÔCO, 2007).
} 


\section{Conclusão}

Neste estudo de investigação, tivemos como objetivo fundamental analisar as perspectivas dos liderados no que concerne à sua percepção das práticas e comportamentos da liderança. Também nos propusemos a averiguar que práticas e comportamentos de liderança deverão ser privilegiados num líder eficaz segundo a perspectiva destes dois grupos. Neste sentido, efetuamos uma reflexão acerca das práticas e comportamentos de liderança de um Presidente do Conselho Executivo de uma Escola Básica com $2^{\circ}$ e $3^{\circ}$ Ciclos da Região Autónoma da Madeira, no que concerne à função de gerir os Recursos Humanos (Pessoal Docente e Não Docente) escolares.

As principais conclusões retiradas foram: 1- a prática de liderança exemplar observada com maior frequência pelos inquiridos no atual Presidente do Conselho Executivo é "Permitir que os outros ajam"; 2 - o PD considera que, no caso de um líder eficaz, deverá ser dada maior relevância à prática "Permitir que os outros ajam" enquanto que o PND a prática que um líder eficaz deverá privilegiar é "Encorajar a vontade"; 3 - os inquiridos consideram que o Presidente do Conselho Executivo adota práticas de uma liderança exemplar, no entanto, a frequência com que estes a percecionam é inferior às que deverão ser observadas, no seu entender, num líder eficaz; 4 - foi o PD que indicou observar com maior frequência no Presidente do Conselho Executivo comportamentos relacionados com as práticas de liderança exemplar.

Os resultados desta investigação deverão ser considerados à luz de algumas limitações nomeadamente, o não ser possível efetuar generalizações dos resultados obtidos a outras organizações escolares e o fato dos resultados obtidos só poderem ser generalizados no caso do PND pois, os resultados do PD só poderão ser conclusivos para os Docentes inquiridos. Em suma, os resultados aqui obtidos devem ser encarados como um ponto de partida para a formulação de outras questões de investigação ou hipóteses a realizar em futuros estudos, pelo que se espera que o mesmo seja, para quem o consulte, considerado um ponto de partida, reflexão e aprendizagem. 


\section{Practices and leadership behaviors in human resource management schools}

\section{Abstract}

In today's globalized and complex world, human capital draws focus in leadership-related areas in educational institutions and the related human resource management. Therefore, we should recognize the perceptions of teachers and staff regarding the practices and behavior related to principals'leadership skills. As its methodological framework, this mixed-nature research examined a case study focusing on the second and third cycles of basic education in a middle school situated in the archipelago of the Autonomous Region of Madeira. The Leadership Practice Inventory (LPI) Observer questionnaire by Kouzes and Posner was administered to the school's teachers and staff. Content analysis focused on the School Educational Project and the Annual School Action Plan. In conclusion, respondents opined that an effective principal should emphasize leadership practices involving notions such as "Enable Others to Act" and "Encourage the Heart".

Keywords: School organizations. Human resource management. Leadership. Leadership practices.

\section{Prácticas y comportamientos de liderazgo en la gestión de recursos humanos de la escuela}

\section{Resumen}

En un mundo globalizado y complejo en el que el capital humano es un tema central asociado a organizaciones de liderazgo escolar y la consecuente Gestión de Recursos Humanos, es urgente comprender cuales percepciones tienen los seguidores, personal docente y no docente, sobre las prácticas y los comportamientos de liderazgo de la escuela. La presente investigación tiene una naturaleza mixta, y privilegió un estudio de caso, que se centró en la Enseñanza Básica del segundo y tercer ciclos de Primaria de la Comunidad Autónoma de la isla de Madeira (RAM), Portugal. Fue administrado, al personal docente y no docente de la escuela, el cuestionario LPI-observador - (Inventario de Prácticas de Liderazgo) de Kouzes y Posner (2003b). El análisis de contenido se centró en el Proyecto Educativo de Escuela y su correspondiente Plan Anual de Estudios. Se concluyó que, según los encuestados, las prácticas de liderazgo deben considerar por preferencia un líder efectivo: "Permitir que otros actúen" y "Alentar la voluntad."

Palabras clave: Organizaciones escolares. Gestión de recursos humanos. Liderazgo. Prácticas de liderazgo. 


\section{Referências}

AFONSO, P. L. Liderança: elementos-chave do processo. Lisboa: Escolar Editora, 2009.

BELL, J. Como realizar um projeto de investigação. Lisboa: Gradiva, 2008.

BENTO, A. Os estilos de liderança dos líderes escolares da Região Autónoma da Madeira. In: SIMPÓSIO SOBRE ORGANIZAÇÃO E GESTÃO ESCOLAR - TRABALHO DOCENTE E ORGANIZAÇÕES EDUCATIVAS, 5., 2008. Actas... Aveiro: Universidade de Aveiro, 2008. (p. 145-157).

BILHIM, J. A. Gestão estratégica de recursos humanos. Lisboa: Instituto Superior de Ciências Sociais e Políticas, 2006.

CAMARA, P; GUERRA, P.; RODRIGUES, J. Novo humanator: Recursos humanos e sucesso empresarial. Alfragide: Dom Quixote, 2010.

CHIAVENATO, I. Teoria geral da administração.4. ed. São Paulo: Makron, 1993. v. 2.

COSTA, J. A. Imagens organizacionais da escola. 3. ed. Porto: ASA, 2003.

COSTA, J. A. Liderança nas organizações: revisitando teorias organizacionais num olhar cruzado sobre as escolas. In: COSTA; J. A.; MENDES, A. N.; VENTURA, A. (Orgs.). Liderança e estratégia nas organizações escolares. Aveiro: Universidade de Aveiro, 2000. p. 15-34.

FONSECA, A. A liderança escolar e a comunicação relacional. In: COSTA; J. A.; MENDES, A. N.; VENTURA, A. (Orgs.). Liderança e estratégia nas organizações escolares. Aveiro: Universidade de Aveiro, 2000. p. 137-52.

FORMOSINHO, J.; MACHADO, J. Autonomia, projecto e liderança. In: COSTA; J. A.; MENDES, A. N.; VENTURA, A. (Orgs.). Liderança e estratégia nas organizações escolares. Aveiro: Universidade de Aveiro, 2000. p. 185-200.

FULLAN, M. The Jossey-Bass reader on educational leadership. San Francisco: Jossey-Bass, 2000.

GREENFIELD, W. Para uma teoria da administração escolar: a centralidade da liderança. In: Sarmento, M. J. (Org.). Autonomia da escola. Políticas e práticas. Porto: Edições ASA, 1999.

GUERRA, M. A. A escola que aprende. 2. ed. Lisboa: ASA, 2000. 
GUERRA, M. A. Entre bastidores: o lado oculto da organização escolar. Porto: Edições Asa, 2002.

HOOPER, A.; POTTER, J. Liderança inteligente: Criar a paixão pela mudança. 8. ed. Lisboa: Atual, 2010.

KOUZES, J. M.; POSNER, B. Z. Inventário das práticas de liderança - LPI. San Francisco: Pfeiffer, 2003a.

. Inventário das práticas de liderança: planejador do desenvolvimento da liderança. San Francisco: Pfeiffer, 2003b. . O desafio da liderança. Casal de Cambra: Caleidoscopio, 2009.

KRAUSE, D. G. A arte da liderança para executivos. Lisboa: Lyon, 1999.

LIMA, L. C. A deliberação democrática nas escolas: os procedimentos gerenciais e as decisões políticas. In: SANCHES, M. et al. (Org.). Cidadania e liderança escolar. Lisboa: Universidade de Lisboa, 2007.

LOPES, A.; BARROSA, L. A comunidade educativa e a gestão escolar: um contributo da gestão estratégica de recursos humanos. Mangualde: Pedago, 2008.

MARÔCO, J. Análise estatística com utilização do SPSS. 3. ed. Lisboa: Sílabo, 2007.

MOTTA, P. R. Gestão contemporânea: a ciência e a arte de se ser dirigente. 10. ed. Rio de Janeiro: Record, 1999.

PROJETO EDUCATIVO DE ESCOLA - PEE. Escola Básica do $2^{\circ}$ e $3^{\circ}$ Ciclos de Santo António. Funchal: Madeira, 2010/2011.

RIBEIRO, M.; BENTO, A. Análise das práticas e dos comportamentos de liderança nos alunos do ensino superior: o caso da população estudantil do instituto politécnico de Bragança. In: CONGRESSO DA SOCIEDADE PORTUGUESA DE CIÊNCIAS DA EDUCAÇÃO, 10., 2009, Bragança, Portugal. Atas... [S.n.t.]. 1 CD-Rom.

. As dimensões e práticas de liderança dos professores/alunos lusobrasileiros do ensino superior: um estudo comparativo. In: CONGRESSO IBEROBRASILEIRO DA POLÍTICA E ADMINISTRAÇÃO DA EDUCAÇÃO, 1., 2010, Elvas, Portugal. Atas... [S.n.t.]. 
RODRIGUES, R. F. Recursos e organizações: colectânea de artigos de opinião (1996-2004). Funchal: ALS, 2008.

SANDBAKKEN, D. A. The factor structure of the Kouzes and Posner Leadership Practices Inventory (LPI) revisited in a Norwegian context. Greenlands: Hesley Management College, 2004. (Working paper series).

SERGIOVANNI, T. J. Novos caminhos para a liderança escolar: uma teoria para a comunidade escolar; a base da liderança escolar; o progresso docente e as escolas como centros de investigação. Porto: ASA:, 2004.

SILVA, A. A. S. Gestão estratégica e projecto educativo. In: COSTA; J. A.; MENDES, A. N.; VENTURA, A. (Orgs.). Liderança e estratégia nas organizações escolares. Aveiro: Universidade de Aveiro, 2000. p. 217-38.

SOUSA, A. Investigação em educação. Lisboa: Livros Horizonte, 2005.

TORRES, L.; PALHARES, J. Estilos de liderança e escola democrática. Revista Lusófona de Educação, Lisboa, n. 14, p. 77-99, 2009.

YIN, R. K. Estudo de caso: planejamento e métodos. Porto Alegre: Bookman, 2001.

\section{Informações dos autores}

Andreia Rubina da Conceição Costa: Mestrado em Ciências da Educação, Universidade da Madeira. Funchal, Portugal. Contato: andreiarcosta2008@hotmail.com

António V. Bento: Doutorado em Educação, Universidade de Massachusetts. Massachusetts, Estados Unidos. Professor Auxiliar de Administração e Gestão Escolar na Universidade da Madeira - UMa. Funchal, Portugal. Membro do Centro de Investigação em Educação (CIE-UMa). Colaborador no programa de acesso ao Mestrado pela UMa no Brasil (Protocolo DH2-UMa). Contato: bento@uma.pt 
